\title{
The Detection of Pathogenic Fungi on Prayer Rugs of The Mosques at Jatinangor Campus of Universitas Padjadjaran
}

\author{
Faturrachman*, Yanti Mulyana** \\ *Faculty of Medicine Padjadjaran University \\ ** Departement of Microbiology and Parasitology, Faculty of Medicine Padjadjaran University \\ Jl. Prof. Eyckman No. 38 Bandung 40161 Indonesia \\ Email: faturrachman8@gmail.com
}

\begin{abstract}
Fungus easily grows in the plateau area with warm moist air. The fungus can enter and contaminate mosque rooms, especially on the surface of prayer rugs. If pathogenic fungi grow on prayer rugs, they can increase the health risk of those who come into contact with them. This research aimed to detect and identify pathogenic fungi on prayer rugs of the mosques in Jatinangor campus of Universitas Padjadjaran using laboratoric descriptive method. The data was collected by sampling of dust from the surface of prayer rugs, fungal culturing and mold identification. The existence of pathogenic fungi has been investigated and observed in twentyeight samples of thirty mosques using simple random sampling. Sabouraud Dextrose Agar was the chosen medium to grow pathogenic fungi. We found fungal growth in all samples with a total of 8 fungal species (Alternaria spp, Aspergillus spp, Candida spp, Fonsecaea spp, Mucor spp, Penicillium spp, Rhizopus spp, Rhodotorula spp) which are opportunistic fungi; however, no pathogenic fungi were found.
\end{abstract}

Keywords : pathogenic fungi, prayer rugs, fungus, Aspergillus spp., Candida spp. 


\title{
Deteksi Jamur Patogen pada Sajadah Masjid/Musholla di Universitas Padjadjaran Kampus Jatinangor
}

\author{
Faturrachman*, Yanti Mulyana** \\ * Fakultas Kedokteran Universitas Padjadjaran \\ ** Departemen Mikrobiologi dan Parasitologi, Fakultas Kedokteran Universitas Padjadjaran \\ Jl. Prof. Eyckman No. 38 Bandung 40161 Indonesia \\ Email: faturrachman8@gmail.com
}

\begin{abstract}
Abstrak
Jamur mudah tumbuh di tempat yang memiliki udara lembab dan hangat. Jamur dapat mengontaminasi ruangan masjid/musholla dan perlengkapannya, terutama sajadah. Risiko gangguan kesehatan akibat jamur patogen dapat dialami oleh orang-orang yang beraktivitas di dalam masjid/musholla dan melakukan kontak dengan sajadah yang terkontaminasi jamur. Tujuan penelitian ini adalah untuk mendeteksi dan mengidentifikasi spesies jamur patogen pada permukaan sajadah masjid dan musholla di lingkungan Universitas Padjadjaran kampus Jatinangor. Desain penelitian yang digunakan adalah deskriptif laboratorium. Data dikumpulkan dengan cara pengumpulan sampel debu pada permukaan sajadah, kultur jamur dan identifikasi jamur secara mikrobiologis. Proses pengumpulan sampel debu dilakukan dari 28 masjid dan musholla di Universitas Padjadjaran yang dipilih dengan sampling acak sederhana. Media Sabouraud Dextrose Agar digunakan untuk menumbuhkan jamur patogen. Dari hasil pemeriksaan mikrobiologis, seluruh sampel menunjukkan pertumbuhan jamur dengan total 8 spesies jamur (Alternaria spp., Aspergillus spp., Candida spp., Fonsecaea spp., Mucor spp., Penicillium spp., Rhizopus spp., Rhodotorula spp.) yang merupakan jamur oportunis dan tidak ditemukan spesies jamur patogen.
\end{abstract}

Kata kunci: jamur patogen, sajadah masjid, fungus, Aspergillus spp., Candida spp. 


\section{Research Article}

\section{Pendahuluan}

Indonesia adalah negara dengan penduduk beragama Islam terbesar di dunia. Data Sensus Penduduk 2010 menunjukkan ada sekitar 88,18\% atau 207 juta jiwa dari total 238 juta jiwa penduduk Indonesia beragama Islam. ${ }^{1}$ Provinsi Jawa Barat memiliki jumlah penganut Islam terbanyak di Indonesia (40.907.538 jiwa) ${ }^{2}$ sehingga banyak masjid didirikan di Jawa Barat untuk memfasilitasi kegiatan keagamaan umat Muslim. Mengingat banyaknya jumlah mahasiswa yang beraktivitas di dalamnya, Unpad memfasilitasi berbagai kegiatan sivitas akademika termasuk peribadahan umat Muslim dengan menyediakan masjid dan musholla yang tersebar di lingkungan kampus Unpad yang berada di Jatinangor.

Masjid pun menjadi salah satu tempat yang paling sering dikunjungi masyarakat untuk melakukan aktivitas ibadah. Umat Muslim melaksanakan sholat dengan menggunakan sajadah, yakni bahan tekstil yang melapisi lantai seperti karpet, tetapi biasanya berukuran lebih kecil daripada karpet rumah. Ruangan masjid dan musholla pada umumnya memiliki ventilasi terbuka dan sering diakses dari luar sehingga berbagai material dari luar dapat masuk ke ruangan masjid dan menjadi polutan, salah satunya adalah jamur.

Jamur adalah salah satu mikroorganisme eukariotik (mempunyai inti sel) yang tidak mempunyai klorofil, memiliki spora sebagai alat penyebaran, struktur somatik atau talus berupa sel tunggal (uniseluler) dan umumnya berupa filamen atau benang-benang bercabang (multiseluler). ${ }^{3}$ Jamur dapat ditemukan di berbagai tempat, baik di luar ruangan seperti di tanah dan di tumbuhan maupun di dalam ruangan dan di tubuh manusia. Ada sekitar 5,1 juta spesies jamur yang sudah teridentifikasi di dunia, akan tetapi hanya sekitar 300 spesies yang dapat menimbulkan penyakit pada manusia. ${ }^{4}$ Beberapa jenis jamur bersifat patogen pada manusia dan dapat menyerang berbagai sistem organ di tubuh manusia, terutama sistem kulit dan respirasi serta menyebabkan munculnya berbagai gejala dan tanda penyakit. Pertambahan jumlah pasien dengan penurunan imun seperti pada penderita HIV/AIDS dicurigai menjadi faktor pemicu utama terjadinya infeksi jamur atau mikosis. ${ }^{5}$

Pada kondisi kelembaban dan suhu lingkungan yang menunjang, beberapa spesies jamur patogen dapat masuk dan tumbuh pada debu rumah (house dust) yang mengandung campuran material organik dan anorganik. Partikel debu yang berada di udara dalam ruangan masjid dapat melekat ke permukaan benda-benda yang ada di ruangan, terutama sajadah yang berada di lantai karena gaya gravitasi yang membuat partikel spora jamur lebih mudah menempel pada permukaan atas sajadah. Selain itu, manusia dapat menjadi agen perantara penyebaran jamur dari luar ruangan ke sajadah jika kondisi higienitas pribadi sebelum masuk ke ruangan masjid terabaikan. Adanya kontak antara manusia dengan sajadah yang terhinggap 


\section{Research Article}

jamur patogen dapat meningkatkan resiko infeksi jamur (mikosis) dan menimbulkan penyakit, terutama pada orang yang menderita penurunan fungsi sistem imun (imunokompromais).

Jamur patogen berupa jamur primer dan oportunistik. Infeksi jamur yang terdiagnosis paling sering disebabkan oleh jamur patogen dari genus Candida, Cryptococcus dan Aspergillus. Penyakit yang sering ditimbulkan oleh jamur patogen di permukaan kulit berupa dermatofitosis athlete's foot (tinea pedis), tinea capitis dan infeksi kuku (tinea unguium). ${ }^{6}$ Pada sistem pernapasan, ukuran partikel jamur yang kecil $(<10 \mathrm{~mm})$ dapat terhirup dan masuk mencapai alveolus paru-paru. Partikel jamur yang masuk bersama debu dan bersifat alergen juga dapat memicu timbulnya berbagai penyakit seperti asma dan aspergilosis bronkopulmonar (salah satu jenis mikosis pulmoner). ${ }^{7}$

Mengingat besarnya risiko infeksi jamur pada manusia dan potensi paparan debu di sajadah Masjid/Musholla Kampus Unpad Jatinangor, penelitian ini bertujuan untuk mengidentifikasi lebih lanjut tentang jamur di sajadah masjid/musholla Unpad Jatinangor. Hal ini diharapkan dapat meningkatkan kewaspadaan terhadap infeksi jamur dan kesadaran diri akan pentingnya manajemen kebersihan sarana masjid kepada Sivitas Akademika Unpad, warga Jatinangor dan masyarakat pada umumnya.

\section{Metode}

Rancangan penelitian ini menggunakan metode penelitian deskriptif yang dilakukan melalui pemeriksaan laboratorium untuk mengidentifikasi jenis jamur pada debu di permukaan sajadah masjid dan musholla di Unpad Jatinangor. Proses identifikasi jamur dilakukan dengan cara pengumpulan sampel debu, kultur jamur dan pengamatan jamur secara makroskopis dan mikroskopis.

Pengumpulan sampel dilakukan dari tanggal 1 November 2017 sampai 5 Desember 2017 di 28 masjid dan musholla beberapa fakultas di lingkungan Unpad Jatinangor. Perhitungan jumlah sampel yang diambil mengacu pada rumus slovin :

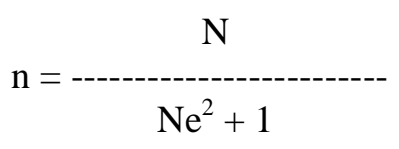

$$
\begin{array}{ll}
\text { Keterangan : } & \mathrm{n}=\text { ukuran sampel } \\
& \mathrm{e}=\text { Margin error, } 5 \%(0,05) \\
& \mathrm{N}=\text { Populasi total, } 30 \mathrm{masjid} / \mathrm{mushola}
\end{array}
$$

Sampel masjid dan musholla kemudian dipilih dengan metode acak sederhana. Kriteria inklusi penelitian berupa sajadah di area masjid/musholla Universitas Padjadjaran yang terdapat debu dan kriteria eksklusi berupa sajadah yang baru dicuci dalam kurun waktu seminggu. Sebelum pengambilan sampel debu, terlebih dahulu mengonfirmasi pencucian sajadah melalui 


\section{Research Article}

pengurus masjid/musholla tersebut. Pengambilan debu dilakukan dengan cara menyedot debu pada permukaan bagian atas sajadah dengan menggunakan vacuum cleaner secukupnya dengan cara zigzag selama 5-10 menit. Debu yang terkumpul lalu dimasukkan pada wadah kontainer yang steril, tertutup rapat kemudian diberi label. Sajadah yang dipilih untuk diambil sampel debunya merupakan beberapa sajadah berbahan kain (berkisar antara 1-4 buah) yang berada di bagian imam, shaf (baris) depan dan pintu masuk dari masjid atau musholla di lingkungan Unpad Jatinangor.

Proses kultur jamur dilakukan dengan terlebih dahulu mencampurkan sampel debu seberat 1-3 gram dengan larutan $\mathrm{NaCl} 0,9 \%$. Kemudian campuran dihomogenkan selama 5 menit dan selanjutnya ditunggu selama 20 menit sampai terjadi pengendapan. Campuran sampel debu-NaCl 0,9\% digoreskan pada media Sabouraud Dextrose Agar (SDA) pada cawan petri dengan menggunakan cotton swab steril dengan membentuk 8 garis simetris, lalu cawan petri ditutup, diisolasi dan dibungkus dengan menggunakan kertas agar tidak ada kontaminasi mikrobiota lain. Isolat diinkubasi pada suhu ruang $\left(25^{\circ} \mathrm{C}\right)$ selama 3-7 hari dan diamati setiap hari guna memantau pertumbuhan jamur dalam rentang waktu tersebut serta mencegah kesulitan identifikasi apabila terjadi sporulasi jamur berlebih.

Pengamatan dilakukan dengan terlebih dahulu mengobservasi morfologi koloni jamur secara makroskopis, baik dalam bentuk, ukuran, warna dan perubahan pigmentasi. Untuk pengamatan mikroskopis, sampel jamur kapang (mold) diambil dari koloni pada media agar dengan selotip transparan yang ditempelkan pada permukaan kaca objek steril yang telah ditetesi larutan lactophenol cotton blue. Untuk jamur ragi (yeast), proses pengambilan dilakukan dengan memakai inokulat loop, lalu digoreskan pada permukaan kaca objek, ditambahkan larutan $\mathrm{KOH} 10 \%$ dan ditutup dengan cover glass. Morfologi jamur kemudian diamati dengan menggunakan mikroskop cahaya pada perbesaran objektif 10x dan 40x dan diidentifikasi spesiesnya berdasarkan atlas mikrobiologi. ${ }^{8}$

\section{Hasil}

Dari hasil pemeriksaan mikrobiologis 28 sampel debu yang terdapat pada sajadah di 28 masjid dan musholla di Universitas Padjadjaran Kampus Jatinangor, seluruh sampel menunjukkan adanya pertumbuhan jamur dengan total 8 spesies jamur yang teridentifikasi. Tipe jamur yang teridentifikasi dari setiap masjid dan musholla dapat dilihat di tabel 1 berikut. 
Tabel 1 Spesies Jamur pada Sajadah Masjid dan Musholla di Unpad Jatinangor

\begin{tabular}{|c|c|c|}
\hline No & Masjid/musholla & Spesies jamur \\
\hline 1 & Musholla F. Farmasi Gedung 1 & Mucor spp \\
\hline 2 & $\begin{array}{l}\text { Masjid F. Teknologi } \\
\text { Pertanian }\end{array}$ & $\begin{array}{l}\text { Aspergillus spp, Rhodotorula spp, Candida spp, } \\
\text { Penicillium spp }\end{array}$ \\
\hline 3 & Musholla C6 & Aspergillus spp, Mucor spp \\
\hline 4 & Masjid F. Ilmu Komunikasi (Putri) & Candida spp, Rhizopus spp \\
\hline 5 & Musholla C4.3 & Penicillium spp \\
\hline 6 & Musholla F. Farmasi Gedung 2 & Candida spp, Rhizopus spp \\
\hline 7 & Musholla C2.2 & Penicillium spp, Rhizopus spp \\
\hline 8 & Masjid F. Pertanian & Penicillium spp \\
\hline 9 & Masjid F. Psikologi & Alternaria spp \\
\hline 10 & Masjid F. Ilmu Budaya (Putri) & Alternaria spp \\
\hline 11 & Masjid F. Ilmu Komunikasi (Putra) & Penicillium spp, Alternaria spp, Rhizopus spp \\
\hline 12 & Musholla F. Keperawatan & Candida spp, Aspergillus spp, Mucor spp \\
\hline 13 & Musholla C5.2 & Mucor spp \\
\hline 14 & Musholla FKG & Penicillium spp \\
\hline 15 & Masjid FMIPA & Aspergillus spp \\
\hline 16 & Musholla C2.3 & Fonsecaea spp \\
\hline 17 & Masjid Raya Universitas Padjadjaran & Aspergillus spp \\
\hline 18 & Musholla F. Farmasi Gedung 3 & Fonsecaea spp \\
\hline 19 & $\begin{array}{l}\text { Masjid F. Perikanan dan Ilmu } \\
\text { Kelautan }\end{array}$ & Fonsecaea spp \\
\hline 20 & Musholla Rektorat & Fonsecaea spp \\
\hline 21 & Musholla C1 (Putra) & Rhizopus spp \\
\hline 22 & Musholla C5.2 & Mucor spp \\
\hline 23 & $\begin{array}{l}\text { Musholla Gedung } \quad \text { Multimedia } \\
\text { Agribisnis }\end{array}$ & Aspergillus spp, Mucor spp, Alternaria spp \\
\hline 24 & Musholla C1 (Putri) & Mucor spp \\
\hline 25 & Masjid F. Ilmu Budaya (Putra) & Aspergillus spp, Mucor spp, Rhizopus spp \\
\hline 26 & Musholla C3.2 & Rhizopus spp \\
\hline 27 & Masjid F. Peternakan & Rhizopus spp \\
\hline 28 & Musholla F. Teknik Geologi & Rhizopus spp \\
\hline
\end{tabular}

Frekuensi dan persentase tiap spesies jamur berdasarkan jumlah masjid dan musholla ditunjukkan pada tabel 2 dan gambar 1.

Tabel 2 Frekuensi dan Persentase Spesies Jamur pada Masjid dan Musholla di Unpad Jatinangor

\begin{tabular}{lcc}
\hline \multicolumn{1}{c}{ Spesies jamur } & $\begin{array}{c}\text { Frekuensi pada } \\
\text { masjid/musholla }\end{array}$ & Persentase $(\%)$ \\
\hline Rhizopus spp & 9 & 20,93 \\
Mucor spp & 8 & 18,6 \\
Aspergillus spp & 7 & 16,37 \\
Penicillium spp & 6 & 14,0 \\
Fonsecaea spp & 4 & 9,3 \\
Candida spp & 4 & 9,3 \\
Alternaria spp & 4 & 9,3 \\
Rhodotorula spp & 1 & 2,3 \\
\hline Total & 43 & 100 \\
\hline
\end{tabular}




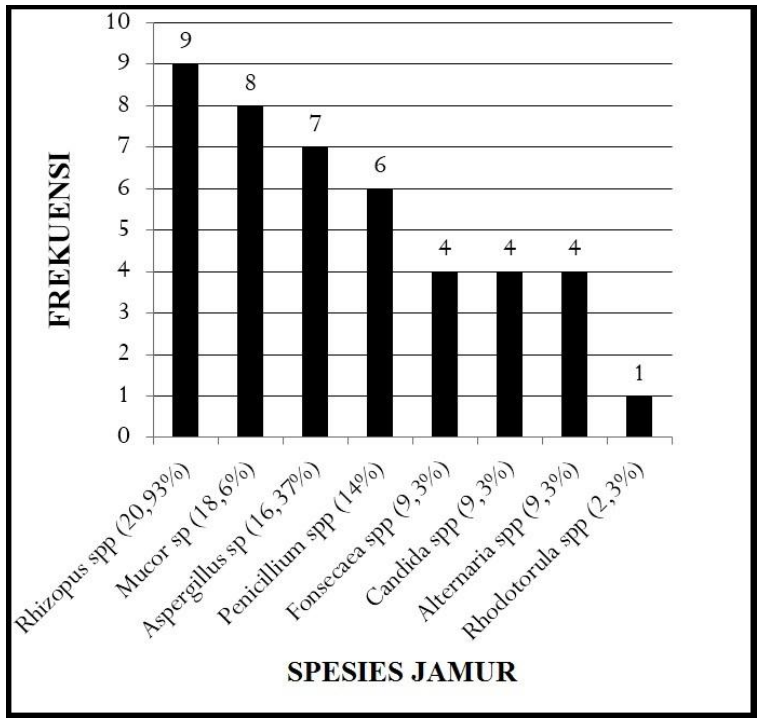

\section{Gambar 1 Diagram Frekuensi dan Persentase Spesies Jamur pada Masjid dan Musholla di Unpad Jatinangor}

Dari tabel dan gambar di atas, spesies jamur yang dominan terdapat di Masjid dan Musholla di Universitas Padjadjaran Kampus Jatinangor adalah Rhizopus spp. (20,93\%), Mucor spp. (18,6\%), Aspergillus spp. (16,37\%) dan Penicillium spp. (14\%) sementara spesies jamur yang paling sedikit muncul adalah Fonsecaea spp., Candida spp., Alternaria spp. (masingmasing 9,3\%) dan Rhodotorula spp. (2,3\%). Berikut ini gambar makroskopis dan mikroskopis dari spesies jamur dominan yang didapatkan pada penelitian ini.
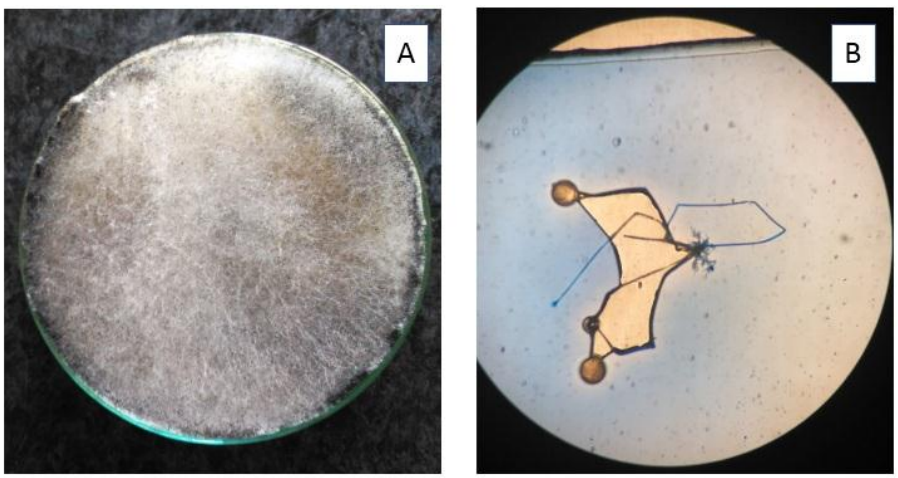

Gambar 2 Rhizopus spp.

Keterangan:

A. Gambaran makroskopik rhizopus yang berbulu menyerupai wol atau kapas putih dan tumbuh memenuhi cawan petri.

B. Gambaran mikroskopik rhizopus dengan perbesaran 40x dan pewarnaan lactophenol cotton blue. Ciri khasnya berupa sporangium bulat dan rhizoid pada pangkal batang (sporangiofor) 


\section{Research Article}
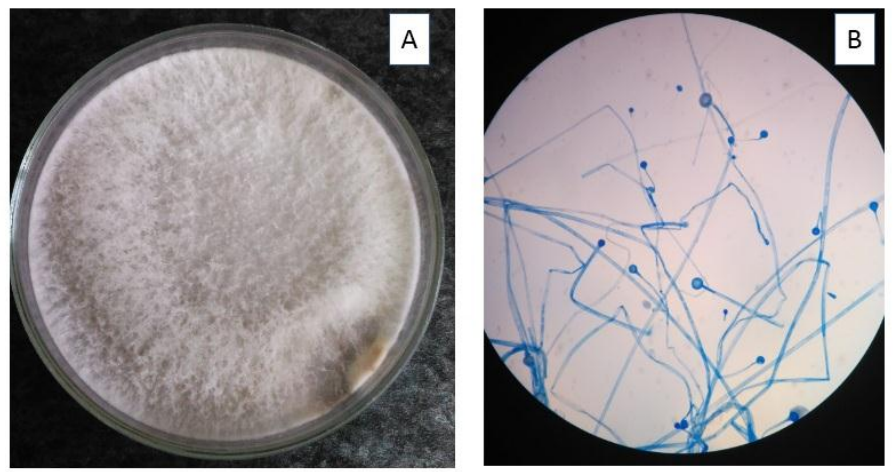

Gambar 3 Mucor spp.

Keterangan:

A. Gambaran makroskopik mucor yang mirip dengan rhizopus, berbulu putih seperti wol. Tumbuh memenuhi cawan petri.

B. Tampak mikroskopik rhizopus dengan perbesaran 40x dan pewarnaan lactophenol cotton blue. Memiliki hifa tak bersepta, sporangium bulat, sporangiofor panjang tanpa disertai rhizoid.
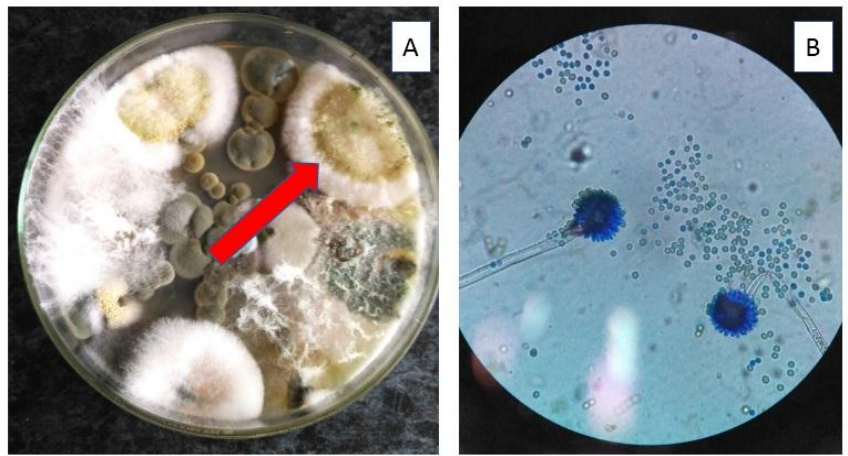

Gambar 4 Aspergillus spp.

Keterangan:

A. Gambaran makroskopik aspergillus (tanda panah merah). Warna koloni bervariasi dari kuning kecoklatan sampai keabuabuan. Teksturnya seperti beludru.

B. Gambaran aspergillus dengan perbesaran 40x dan pewarnaan lactophenol cottton blue. Mempunyai hifa bersepta dengan konidiofor (batang) berdinding halus. Ciri khasnya berupa konidia halus yang menyebar di sepanjang sisi vesikula (bagian kepala) aspergillus.
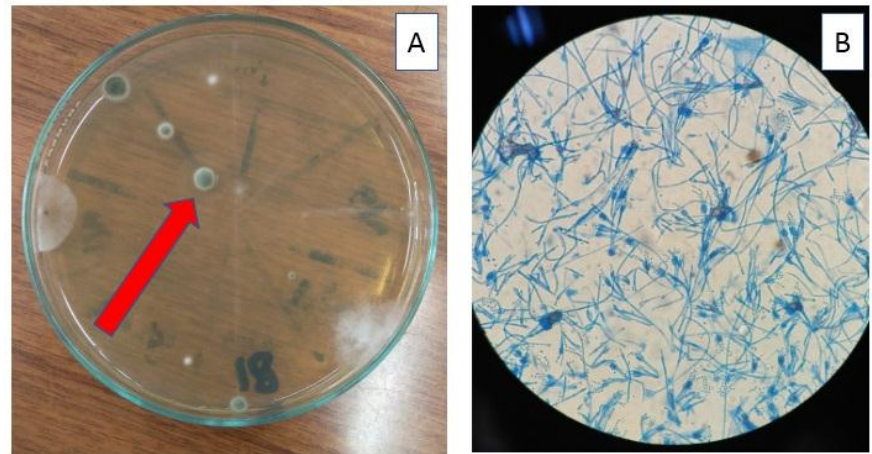

Gambar 5 Penicillium spp.

Keterangan:

A. Gambaran makroskopis Penicillium yang bertekstur beludru bertepung dengan variasi warna hijau dan hijau keabu-abuan bertepi putih.

B. Tampilan mikroskopis Penicillium yang memiliki septa dengan hifa berhialin. Sebagian besar konidiofor bercabang. Ciri khasnya berupa bagian kepala (konidiofor) bercabang yang terdiri atas metulae dan fialid yang menghasilkan konidia. Percabangan ini memberi tampilan khas menyerupai sikat atau penicillus (Latin). 


\section{Diskusi}

Tidak ditemukan adanya jamur patogen (jenis jamur dermatofita: genus Epidermophyton, Microsporum dan Trichophyton) yang teridentifikasi. Sebagian besar spesies jamur yang ditemukan merupakan jamur oportunis yang hanya menimbulkan manifestasi klinis pada individu dengan sistem imun rendah. Tidak ditemukannya jenis jamur dermatofita seperti Microsporum canis disebabkan masa maturitas dermatofita memerlukan waktu yang lebih lama (6-10 hari). ${ }^{9}$

Dua spesies jamur terbanyak, Rhizopus spp. dan Mucor spp. merupakan golongan jamur zygomycota yang dapat tumbuh di berbagai lingkungan dan sebagian besar merupakan mesofilik yang tumbuh pada suhu $10-40^{\circ} \mathrm{C}$ dengan suhu optimal $20-35^{\circ} \mathrm{C}$. Dari penelitian ini, kedua genus jamur tersebut ditemukan dari sajadah-sajadah di ruangan musholla yang memiliki sistem ventilasi buruk, tertutup, berkelembaban tinggi dan berdebu. ${ }^{10}$

Menurut penelitian Jean-Ralph Zahar (2016), banyaknya Aspergillus spp. yang ditemukan pada ruangan rumah sakit dengan karakteristik terbuka dan memiliki sistem ventilasi yang baik, diduga Aspergillus spp. yang banyak terdapat di tanah sebagai saprofit, masuk ke dalam ruangan melalui kondisi meteorologi/cuaca kemarau yang menyediakan kelembaban dan suhu yang memungkinkan. ${ }^{11}$ Sesuai dengan penelitian tersebut, peneliti juga menemukan banyaknya Aspergillus spp. pada masjid/musholla yang mempunyai ruangan yang luas seperti pada Masjid Raya Unpad dan Masjid FMIPA. Perbedaan jenis dan kuantitas jamur yang ditemukan pada tiap masjid dan musholla kemungkinan disebabkan oleh perbedaan kualitas udara, luas ruangan, jumlah jama'ah, kondisi gedung, banyaknya ventilasi udara dan higienitas sajadah antar masjid/musholla. ${ }^{12}$

Terdapat perbedaan jenis dan jumlah spesies jamur antar masjid dan musholla. Pada masjid atau musholla yang ramai dan memiliki ruangan yang luas seperti Masjid Raya Unpad dan Masjid Fakultas Peternakan, meskipun memiliki ventilasi yang banyak dan terbuka, jamur tetap rentan mengontaminasi disebabkan debu dan jamur dari luar ruangan (tanah) dapat masuk ke ruangan dengan bantuan angin melalui ventilasi. ${ }^{13}$ Pada penelitian Namita Kumari et al (2016) di India, didapatkan hasil genus jamur Aspergillus, Penicillium, Rhizopus dan Alternaria seringkali muncul di dalam ruangan demikian pula yang dtemukan dalam penelitian ini. ${ }^{14}$ Mostafa Chadeganipour et al (2010) melaporkan Penicillium spp., Cladosporium spp., Aspergillus spp. dan Alternaria spp. banyak ditemukan pada sampel udara di Isfahan, Iran. Akan tetapi pada penelitian tersebut, Rhizopus spp. termasuk salah satu jamur yang mempunyai prevalensi paling rendah. ${ }^{15}$ Fakta tersebut kontradiktif terhadap penelitian ini yang mana didapatkan Rhizopus spp. menjadi spesies jamur yang paling sering ditemukan. 


\section{Research Article}

Adanya jamur pada permukaan sajadah diduga disebabkan oleh beberapa alasan. Pertama, bisa jadi disebabkan kurangnya pembersihan sajadah, baik dengan cara dicuci atau dihisap dengan mesin penghisap (vacuum cleaner). Selain itu, beberapa faktor seperti kontak permukaan sajadah dengan lingkungan dalam ruang (indoor environment), kurangnya higienitas pengguna sajadah terutama dengan keadaan kaki yang basah ataupun kotor, kondisi ruangan masjid/musholla yang tertutup, luas ruangan yang sempit, sedikit terkena paparan sinar matahari serta sistem ventilasi ruangan yang buruk turut membantu menciptakan kondisi yang optimal bagi pertumbuhan jamur. ${ }^{16}$

Kontaminasi jamur pada sajadah ditentukan oleh kualitas udara dalam ruangan masjid/musholla, baik kualitas fisik, kimia maupun biologis. Secara fisik, kualitas udara ditentukan oleh suhu, kelembaban udara dan keadaan ventilasi. Pada ruangan dengan ventilasi yang tidak adekuat, suplai udara berikut distribusi dan pertukarannya menjadi sedikit sehingga debu di dalam ruangan tertahan, tidak dapat keluar dan mengontaminasi ruangan secara kimiawi. ${ }^{16}$ Selain itu, ventilasi yang buruk dapat memicu kondisi suhu dan kelembaban yang optimal bagi pertumbuhan jamur, sehingga jamur mengkontaminasi ruangan, termasuk pada aksesoris dalam ruangan seperti karpet atau sajadah. Kontak manusia dengan jamur dapat mengganggu aktivitas di dalam ruangan dan meningkatkan risiko timbulnya masalah kesehatan seperti alergi, infeksi dan toksisitas. ${ }^{17}$

Berbagai komponen jamur dalam ruangan seperti spora jamur dan produk metabolismenya seperti mikotoksin, dinding sel, senyawa organik volatil dan antigen sel jamur dapat menimbulkan masalah kesehatan manusia terutama pada orang dengan penyakit pernafasan, bayi, orang tua, dan pasien yang sedang menjalani terapi imunosupresif. ${ }^{18}$ Penyakit lain yang dapat timbul akibat infeksi jamur dapat berupa mikosis superfisial, mikosis kutan, mikosis subkutan sampai mikosis sistematik yang menginfeksi organ dalam seperti paru-paru, rektum, uretra dan organ lain secara luas yang dapat berakibat fatal. ${ }^{19}$

Paparan jamur dalam ruangan tidak dapat disingkirkan secara sempurna, akan tetapi dapat dikurangi dengan melakukan upaya kontrol dan pencegahan guna menurunkan kontaminasi jamur pada sajadah. ${ }^{20}$ Upaya yang dapat dilakukan yakni: 1) Pembersihan rutin dengan pencucian sajadah atau penyedotan debu menggunakan vacuum cleaner untuk mengurangi jumlah spora. Kegiatan penyedotan debu dapat dilakukan di akhir pekan atau saat ruangan tidak digunakan dengan menggunakan masker untuk mencegah timbulnya gejala alergi akibat polusi udara dalam ruangan ketika proses pembersihan, 2) Penggantian sajadah dengan permukaan lantai yang keras (baik bermaterial ubin maupun kayu) untuk mengurangi kontaminasi jamur, ${ }^{19}$ 3) Melipat sajadah dengan benar setelah penggunaan dan meletakkannya 


\section{Research Article}

di lemari tertutup untuk menghindari kontak permukaan sajadah dengan udara ruangan sehingga dapat mengurangi kontaminasi debu dan jamur.

\section{Simpulan}

Hasil dari penelitian menunjukkan adanya jamur pada permukaan sajadah di 28 masjid dan musholla Unpad Jatinangor dengan didapatkannya pertumbuhan jamur dengan total 8 spesies jamur oportunis (Alternaria spp., Aspergillus spp., Candida spp., Fonsecaea spp., Mucor spp., Penicillium spp., Rhizopus spp., Rhodotorula spp.) yang merupakan jamur oportunis dan tidak ditemukan spesies jamur patogen.

Hal ini dikarenakan kondisi fisik, kelembaban udara yang tinggi dan suhu ruangan masjid/musholla yang relatif rendah sehingga jamur-jamur yang berasal dari tanah dapat masuk ke ruangan, tumbuh dan mengkontaminasi aksesoris di dalam masjid dan musholla, terutama sajadah. Mengingat jamur oportunis dapat berisiko menimbulkan penyakit pada orang-orang dengan kondisi tertentu yang memakai fasilitas masjid/musholla, maka direkomendasikan agar kegiatan pembersihan ruangan dan sajadah masjid/musholla di Unpad Jatinangor dapat digalakkan sebagai upaya menjaga sanitasi lingkungan dalam ruangan.

\section{Daftar Pustaka}

1. Badan Pusat Statistik. Statistik Indonesia 2013 [Internet]. 1st ed. Subdirektorat Indikator Statistik, editor. Katalog BPS. Jakarta: Badan Pusat Statistik; 2013. p. $78 . \quad$ Available from : https://www.bps.co.id/website/pdf_publikasi/watermark_Statistik_Indonesia_2013.pdf

2. Badan Pusat Statistik Provinsi Jawa Barat. Jawa Barat Dalam Angka 2016 [Internet]. Bandung: BPS Provinsi Jawa Barat; $2016 . \quad$ p. $68 . \quad$ Available from: https://jabar.bps.go.id/publication/2016/07/15/2297a52073f5f32eca26eb8a/provinsi-jawa-barat-dalam-angka2016.html

3. Sutanto I, Ismid IS, Sjarifuddin PK, Sungkar S. Buku Ajar Parasitologi Kedokteran. 4th ed. Jakarta: Fakultas Kedokteran Universitas Indonesia; 2008. p. 151.

4. Blackwell M. The fungi: 1, 2, 3 ... 5.1 million species? Am J Bot. 2011;98(3):426-38.

5. Armstrong-James D, Meintjes G, Brown GD. A neglected epidemic: Fungal infections in HIV/AIDS. Trends Microbiol. 2014;22(3):120-7.

6. Brown GD, Denning DW, Gow NAR, Levitz SM, Netea MG, White TC. Hidden Killers: Human Fungal Infections. Sci Transl Med. 2012;4(165rv13):1-9.

7. Iqbal N, Irfan M, Zubairi ABS, Jabeen K, Awan S, Khan JA. Clinical manifestations and outcomes of pulmonary aspergillosis: experience from Pakistan. BMJ Open Respir Res. 2016;3(1):155.

8. Leboffe MJ, Pierce BE. A Photographic Atlas for the Microbiology Laboratory 4Ed. 4th ed. Microbiology lab. Colorado: Morton Publishing Company; 2011. p. 183-192.

9. Sharma A, Chandra S, Sharma M. Difference in keratinase activity of dermatophytes at different environmental conditions is an attribute of adaptation to parasitism. Mycoses. 2012;55(5):410-5.

10. Dedesko S, Siegel JA. Moisture parameters and fungal communities associated with gypsum drywall in buildings. Microbiome. 2015;3:71.

11. Pilmis B, Thepot-Seegers V, Angebault C, Weiss E, Alaabouche I, Bougnoux ME, et al. Could we predict airborne Aspergillus contamination during construction work?. Am J Infect Control. 2017;45(1):39-41.

12. Cabral JPS. Can we use indoor fungi as bioindicators of indoor air quality? Historical perspectives and open questions. Sci Total Environ. 2010;408(20):4285-95.

13. Adams RI, Miletto M, Taylor JW, Bruns TD. Dispersal in microbes: Fungi in indoor air are dominated by outdoor air and show dispersal limitation at short distances. ISME J. 2013;7(7):1262-73.

14. Kumari N, Kumar A, Khare P. Fungal pollution in indoor environments. IOSR J Pharm Biol Sci. 2016;11(1):5-7.

15. Chadeganipour M, Shadzi S, Nilipour S, Ahmadi G. Airborne fungi in Isfahan and evaluation of allergenic responses of their extracts in animal model. Jundishapur J Microbiol. 2010;3(4):155-60. 


\section{Research Article}

16. Fitria L, Wulandari RA, Hermawati E, Susanna D. Kualitas Udara Dalam Ruang Perpustakaan Universitas X Ditinjau dari Kualitas Biologi, Fisik, dan Kimiawi. Makara Kesehatan. 2008;12(2):76-82.

17. Ahsani D. Respon Imun Pada Infeksi Jamur. JKKI. 2014;6(2):55-66.

18. Ayanbimpe GM, Wapwera SD, Kuchin D. Indoor air mycoflora of residential dwellings in jos metropolis. Afr Health Sci. 2010;10(2):172-6.

19. Khan AAH, Karuppayil SM. Fungal pollution of indoor environments and its management. Saudi J Biol Sci. 2012;19(4):405-26.

20. Uzochukwu OV, Nkpouto U. Airborne Fungi in the Indoor and Outdoor Environments. Int J Adv Biol Res. 2013;3(1):9-12. 